\title{
Drone Operated Crop Monitoring and Agrochemical Spraying in Agriculture
}

\author{
Gopinath, Kapildeo Mandal, Taj Mahammad Ansari, Ritesh Yadav
}

\begin{abstract}
Agriculture plays a strategic role in a country's economic development process. In order to raise the farm productivity and to develop proficient administration, it is crucial to look into the growth of the crops, then the surrounding environment and farming operations. Earlier most of the human communities fully depend on agriculture for their survival. But now the scenario is totally opposite due to various reasons. It is our duty and also important to consider the proper and smart utilization of good resources. The main issue nowadays is using agro chemicals. To have a good resource it is mandatory to use agrochemicals in agriculture to maintain the quality of the plants. In agricultural crop fields, agrochemicals are generally used to increase productivity and improve quality. Through improved spraying effectiveness, the amount of pesticide used in agriculture can be minimized and the risk of environmental damage can be mitigated. However direct contact with these agro chemicals can result in various diseases like cancers, birth defects, reproductive dysfunction, nausea, rashes etc. Also most of the agro chemicals are wasted during the time of spray. But if agrochemical is used, then it will improve agricultural quality production. By considering all these, a new system is proposed which consists of Drone, Tank for agrochemical, Camera and Controllers and other supporting mechanisms. The proposed system will be operated by a human over the farming filed and monitors all the area through the camera. The proposed system will give the details of affected area alone, so that only those areas can be sprayed with the help of micro nozzle. Due this human contact will be avoided, amount of agrochemicals used will be reduced, the quality and production of crop will be increased. Also it will reduce the cost of agrochemicals used.
\end{abstract}

Keywords: Agriculture, Drone, plant, thermal and heat seeking camera, UAV.

\section{INTRODUCTION}

Drones were in used since 1980's and the implementation and features are blooming widely to reach the demands of raised food production and population of fellow humans [1]. so that one area, agriculture sector that has seen little attention from drones [2]. As drone and internet of things has become more popular. A variety of IOT technologies can be incorporated into agriculture to help improve the field of agriculture [3]. Drone will have a crucial requirement on the agricultural firms as they can track many criteria's of farming which peer on farming techniques cannot accomplish. Drone with camera can provide a clear picture of the entire area of the field as well as the area of land used; this data can allow a

Revised Manuscript Received on December 30, 2019.

N.P. Gopinath *, Assistant Professor, Department of Electrical and Electronics Engineering, AVIT, Chennai, India.

Kapildeo Mandal, Taj Mahammad Ansari , Ritesh Yadav, UG scholar, Department of Electrical and Electronics Engineering, AVIT, Chennai, India. farmer to maintain the need for agricultural process parameters [4]. These results in higher crops in production increased. Drones are also easier to use and farmers can easily collect reliable, real-time data [5]. The drone interfaced with Raspberry Pi and camera to analyze the affected crops [6-7]. Thus, a drone that is adequately equipped with variable tools and technology can make agriculture efficient, accurate. Simplified field of agriculture drone is shown in fig.1.

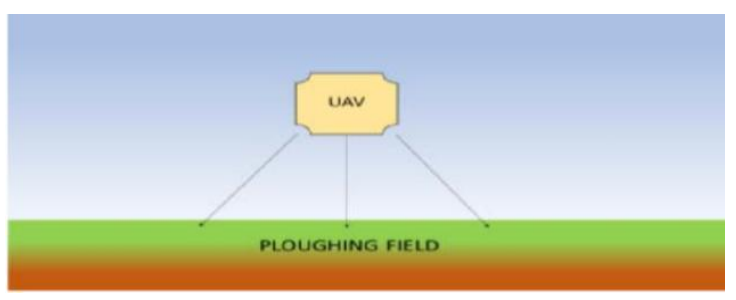

Fig. 1.Simplified Field of Agriculture Drone

\section{PROPOSED SYSTEM}

Using cameras can greatly help farm management by tracking plant and crop thermal properties. One more feature which can be mounted in the proposed system is an RGB-D camera to capture and process the image in real time.

\section{A. Block Diagram}

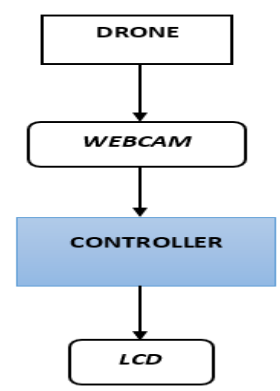

Fig. 2.Block Diagram of Proposed Model

\section{B. Working}

We have suggested a detailed farm control method. It helps the image processing technique were used for auditing the agricultural yards by mean of drone and camera.

Drone was connected with webcam which captures the image of field crop and by the help of python code we do the image processing on the crop pictures.

After we analyses the image by real time application of drone interfaced with camera. 


\section{Drone Operated Crop Monitoring and Agrochemical Spraying in Agriculture}

So that analyzation of the affected plant can be done and the pesticides can be sprayed only on affected plant. Fig. 3 and 4 shows the processing and analyzation of healthy and affected crop.
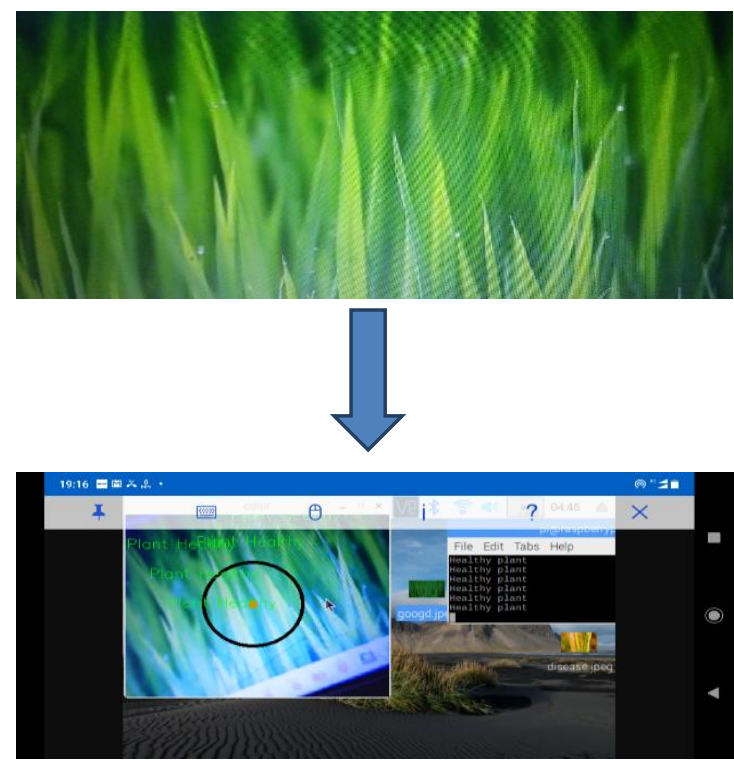

Fig. 3.Live demonstration of Healthy Crops
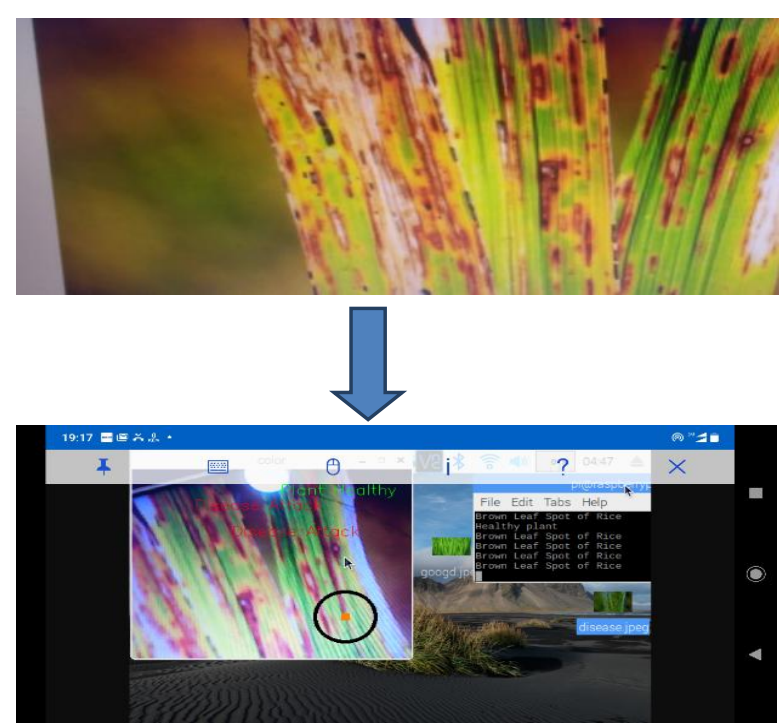

Fig. 4.Live Demonstration of Affected Crops

\section{Benefits}

The device is having following benefits

- Increased quality of production

- Remote monitoring

- Real time data

- Less use of pesticides

- Less contact with human from pesticides.

D. Novelty

- Image processing is used to find the affected plants in the field.

- Wireless application to control the system.

\section{RESULT AND DISCUSSION}

\section{A. Raspberry Pi Model 3 B}

It is the current technique in the field of embedded system raspberry pi 3rd generation model is shown in fig.5. It is a low-cost ARM based and lightweight SBC (Single Board Computer) developed by the Raspberry Pi Authority. Using this processor or embedded system, we can transmit the digital parameter which is similar to any cloud based storage area over the internet. The data thus obtained saved finds use for auditing requirements as well as for information analysis. The RGB-D a camera module which can be built into the Raspberry Pi system so that information acquired through it can be sent to cloud storage.

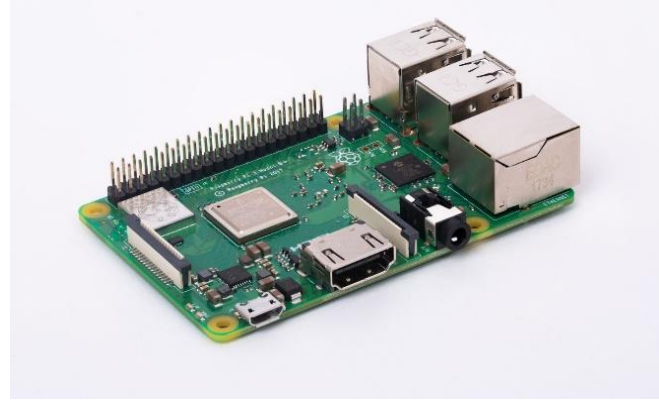

Fig. 5.Raspberry Pi

\section{B. Webcam}

A webcam is a tiny, indirectly or directly linked digital video camera to a PC or group of PC network.

It is interface with software to help users capture or stream video from the Web on the device. It is capable of taking high definitions pictures, videos with high quality when compared to other cameras which is available in our market. Web cameras are also known as webcams is represent in fig.6.

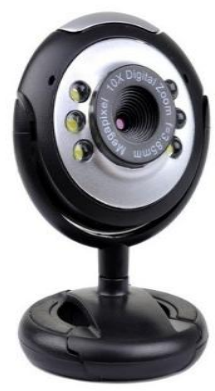

Fig. 6. Webcam

\section{Drone}

Drone is nothing but a plane with a auto pilot mode or unmanned aerial vehicle and it is shown in fig. 7. UAVs are an inevitable part of an unmanned aircraft system which consists of UAV, a ground-based module or a controller and a link system between them. The UAVs can be controlled with various degrees of methods either under a man's control through a remote or through onboard computers (without disclosing the users info) unknowingly. 


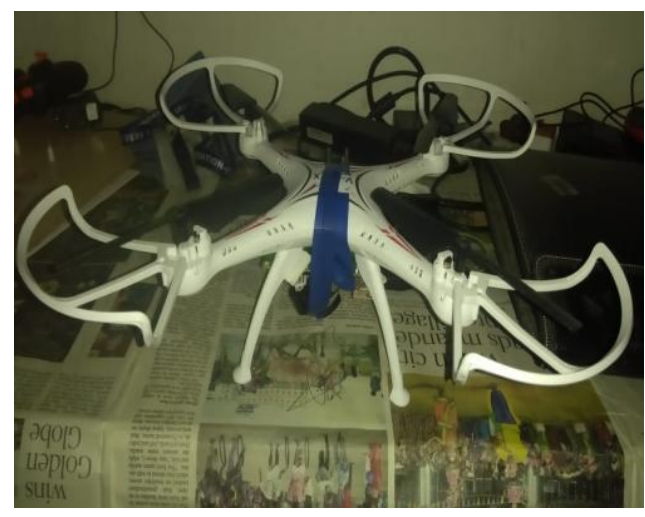

Fig. 7. Drone

\section{CONCLUSION}

We can end up with a fact that UAVs or drones and camera interfaced with Raspberry Pi will be very helpful in the field of farming with the abrupt raise in human all around the worlds as they are important at the very initial stage of a crops life. It would no decrease the duration; instead it will increase plant performance on the basis of gathered data. Due to system auditing crop management would be very efficient. With lower energy consumption, the rate of production will increase rapidly according to advanced technologies. Monitoring a farm is a much simpler and more reliable way than walking it.

\section{REFERENCES}

1. G. Pasolini, A. Bazzi and F. Zabini, "A Raspberry Pi-Based Platform for Signal Processing Education”, IEEE Signal Processing Magazine, 34(4), Jul.2017, pp.151-158.

2. A. N. Toosi, J. Son and R. Buyya, "Clouds-pi: A low-cost raspberry-pi based micro data center for software-defined cloud computing", IEEE Cloud Computing, 5(5), Oct.2018, pp.81-91.

3. M. Gareth, "The Raspberry Pi single-board computer will revolutionise computer science teaching",Engineering \& Technology, 7(3), Apr.2012, pp.26-26.

4. H. N. Saha, A. Mandal and A. Sinha, "Recent trends in the Internet of Things. In annual computing and communication workshop and conference (CCWC), Jan.2017, pp.1-4.

5. Pi, R., Available online: https://en. wikipedia. org/wiki. Raspberry_Pi, Sep.2016

6. M. Rouse, “ Definition: drone" . Retrieved from Internet of Things Agenda: http://internetofthingsagenda.techtarget.com/definition/drone. 2016 .

7. J. Amjath Ali, B. Thangalakshmi, and A. V. Beaulah,, "IoT Based Disaster Detection and Early Warning Device," International Journal of MC Square Scientific Research, vol. 9, no. 3,2017, pp. 20-25.

\section{AUTHORS PROFILE}

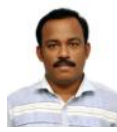

N.P.Gopinath. He received his B.E in Electrical and Electronics Engineering (2009) from Noorul Islam College of Engineering and M.Tech in Power Electronics \& Drives (2013) from SRM University. He has more than 10 publications in the field of Power Electronics. He is research scholar in Department of Electrical Engineering,

Vinayaka Missions Research Foundation. His research interests include Control System Applications to Power Electronics.
Taj Mahammad Ansari UG Student. Department of EEE. AarupadaiVeedu Institute of Technology. Chennai

Ritesh Yadav UG Student. Department of EEE. Aarupadai Veedu Institute of Technology. Chennai

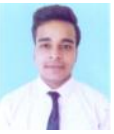

